\title{
Prevalence of potential drug-drug interactions in cancer patients treated with oral anticancer drugs
}

\author{
R W F van Leeuwen ${ }^{\star}, 1,2$, D H S Brundel ${ }^{2}$, C Neef $^{2}$, T van Gelder ${ }^{1,3}$, R H J Mathijssen ${ }^{4}$, D M Burger ${ }^{5}$ \\ and F G A Jansman ${ }^{6,7}$
}

${ }^{1}$ Department of Pharmacy, Erasmus University Medical Center, 's-Gravendijkwal 230, Rotterdam 3015CE, The Netherlands; ${ }^{2}$ Department of Clinical Pharmacy and Toxicology, Maastricht University Medical Center, P. Debyelaan 25, Maastricht 6229HX, The Netherlands; ${ }^{3}$ Departments of Internal Medicine and Hospital Pharmacy, Erasmus University Medical Center, 's-Gravendijkwal 230 230, Rotterdam 3015CE, The Netherlands; ${ }^{4}$ Department of Medical Oncology, Erasmus University Medical Center, Daniel den Hoed Cancer Center, 's-Gravendijkwal, Rotterdam 3015CE, The Netherlands; ${ }^{5}$ Department of Pharmacy, Radboud University Center for Oncology (RUCO), Radboud University Medical Center, Geert Grooteplein 10, Nijmegen 6526 GA, The Netherlands; ${ }^{6}$ Department of Clinical Pharmacy, Deventer Hospital, Nico Bolkesteinlaan 75, Deventer 7416SE, The Netherlands and ${ }^{7}$ Department of Pharmacotherapy and Pharmaceutical Care, State University Groningen, Antonius Deusinglaan 1, Groningen 9713 $A V$, The Netherlands

Background: Potential drug-drug interactions (PDDIs) in patients with cancer are common, but have not previously been quantified for oral anticancer treatment. We assessed the prevalence and seriousness of potential PDDls among ambulatory cancer patients on oral anticancer treatment.

Methods: A search was conducted in a computer-based medication prescription system for dispensing oral anticancer drugs to outpatients in three Dutch centres. Potential drug-drug interactions were identified using electronic (Drug Interaction Fact software) and manual screening methods (peer-reviewed reports).

Results: In the 898 patients included in the study, 1359 PDDls were identified in 426 patients $(46 \%$, 95\% confidence interval $(\mathrm{Cl})=42-50 \%)$. In 143 patients (16\%), a major PDDI was identified. The drug classes most frequently involved in a major PDDI were coumarins and opioids. The majority of cases concerned central nervous system interactions, PDDIs that can cause gastrointestinal toxicity and prolongation of QT intervals. In multivariate analysis, concomitant use of more drugs (odds ratio (OR) $=1.66,95 \%$ $\mathrm{Cl}=1.54-1.78, P<0001)$ and genito-urinary cancer $(\mathrm{OR}=0.25,95 \% \mathrm{Cl}=0.12-0.52, \mathrm{P}<0001)$ were risk factors.

Conclusion: Potential drug-drug interactions are very common among cancer patients on oral cancer therapy. Physicians and pharmacists should be more aware of these potential interactions.

Drug-drug interactions in patients with cancer are common, and most drug-drug interactions can cause considerable adverse drug reactions (ADRs) (Köhler et al, 2000). In the general population, it has been reported that $20-30 \%$ of all ADRs are caused by drug- drug interactions (Köhler et al, 2000). Drug-drug interactions are estimated to be the cause of death in $\sim 4 \%$ of cancer patients (Buajordet et al, 2001). Patients treated systemically for cancer are particularly at risk for drug-drug interactions. Typically, patients

*Correspondence: Dr RWF van Leeuwen; E-mail: r.w.f.vanleeuwen@erasmusmc.nl

This study was presented at the 37th ESMO Annual Meeting (Vienna, Austria, 28 September to 2 October 2012, \#1402).

Received 16 November 2012; revised 16 January 2013; accepted 17 January 2013; published online 14 February 2013

(c) 2013 Cancer Research UK. All rights reserved 0007-0920/13 
with cancer receive a high number of drugs concomitantly, including cytotoxic agents, hormonal agents, targeted agents, and supportive care agents among medication prescribed to treat comorbidities. An additional problem is that the mean age of cancer patients is increasing. Older patients generally have more comorbidities for which they also receive drug treatment (Yancik and Ries, 2000). The risk for drug-drug interactions in elderly cancer patients is further increased because of altered age- and comorbidity-related physiologic changes (e.g., altered drug absorption due to mucositis or altered excretion due to renal and hepatic impairment) (Scripture and Figg, 2006).

Here, a potential drug-drug interaction (PDDI) was defined as the occurrence of a potentially harmful combination of prescribed drugs in a given patient, rather than the occurrence of an actual adverse event for a patient.

In clinical practice, PDDIs can be distinguished as pharmaceutical, pharmacokinetic, and pharmacodynamic interactions (Scripture and Figg, 2006). Pharmaceutical PDDIs occur for instance when two chemically or physically incompatible compounds are combined (e.g., cisplatin and mesna; Verschraagen et al, 2003). Pharmacokinetic interactions refer to an influence on the absorption, distribution, metabolism, or elimination of the drug itself or a combination of drugs. A common pharmacokinetic interaction concerns drugs metabolised by the cytochrome P450 (CYP) enzymes. By inhibition or induction of CYP iso-enzymes, blood and tumour concentrations, antitumoural effects, and toxicities of specific anticancer therapies may be altered. Other pharmacokinetic interactions may result from, that is, inhibition of the ABCB1 efflux-transporter (or P-glycoprotein); by altering the activity of $\mathrm{ABCB} 1$, the bioavailability of anticancer drugs may be influenced. Pharmacodynamic drug interactions usually occur when two or more drugs have a similar mechanism of action. The effect can be synergistic, additive, or antagonistic. Pharmacodynamic drug interactions can be beneficial (e.g., enhanced pharmacologic effects with fluorouracil and leucovorin), but may also be potentially harmful (e.g., ototoxicity with furosemide and cisplatin; Brummett, 1981).

In general medicine, the prevalence of PDDIs and their determinants has been evaluated in several studies (Egger et al, 2003; Geppert et al, 2003; Glintborg et al, 2005). By contrast, data on the prevalence of PDDIs with anticancer drugs are scarce. Two studies, conducted in ambulatory cancer patients, found that $27-58 \%$ of all patients had at least one PDDI (Riechelmann et al, 2007; van Leeuwen et al, 2011). Determinants for PDDIs were an increasing number of drugs, the use of OTC drugs, type of medication (drugs to treat comorbid conditions only), and the presence of brain tumours. However, these studies included only outpatients receiving intravenous anticancer treatment at a daytreatment facility (Riechelmann et al, 2007; van Leeuwen et al, 2011). A retrospective database study, involving cancer patients on oral anticancer therapy, found that $5 \%$ of all patients had at least one potentially interacting drug combination (Ko et al, 2012).

In the last decade, the availability and use of oral anticancer agents has increased dramatically. In comparison with parenteral treatment, the administration of oral agents is usually believed to be more convenient for the patient (Aisner, 2007). However, due to chronic use and the fact that most anticancer drugs are metabolised by CYPs (Scripture and Figg, 2006), patients on oral anticancer agents are at considerable risk for PDDIs. Moreover, a relative lack of collaboration between medical oncologists, pharmacists, and general practitioners, and the fact that computer-based medication prescription systems in hospitals and community pharmacies are usually not connected leads to PDDIs frequently going unnoticed (Aisner, 2007).

At present, epidemiological data regarding harmful PDDIs during oral anticancer therapy are scarce in the literature. Therefore, the aim of this study was to investigate the prevalence of PDDIs among ambulatory cancer patients on oral anticancer treatment, with the primary intent to create awareness among oncologists and pharmacists regarding the risk of potentially harmful drug-drug interactions. The secondary objective was to obtain more insight into possible determinants for the occurrence of these PDDIs.

\section{MATERIALS AND METHODS}

Study design and patients. A multicentre cross-sectional study of the prevalence of PDDIs was conducted in ambulatory cancer patients treated with oral anticancer drugs in three Dutch centres: the Maastricht University Medical Center (Maastricht), St. Radboud University Medical Centre (Nijmegen), and Deventer Teaching Hospital (Deventer). All ambulatory patients with the diagnosis of a solid tumour or a haematological malignancy, who were receiving one of more oral anticancer therapies (with or without additional intravenous anticancer drugs), were included in the study. Exclusion criteria were (i) the use of (oral) experimental trial agents, (ii) age $<18$ years, and (iii) the use of oral anticancer drugs for non-malignant diseases. This study was registered under number ISRCTN01739090, and was approved by the medical ethics boards of all three participating institutes.

Procedures. A retrospective search was conducted in the computer-based medication prescription system of the hospital pharmacy in these three centres for the dispensing of oral anticancer drugs to outpatients over a period of 12 months (between 1 October 2010 and 1 October 2011). Medications were classified into three groups; 'anticancer drugs', 'supportive care drugs', and 'drugs to treat additional diseases/comorbidities'. Anticancer drugs were defined as oncolytic drugs (Anatomical Therapeutic Chemical code (ATCcode) L01) and antihormonal agents (ATC-code L02). In addition, data on supportive care and co-medication were collected using the same computer-based medication prescription system of the hospital pharmacy. Supportive care drugs included antiemetic and analgesic drugs. Drugs for chronic and incidental use (e.g., dexamethasone during chemotherapy) were included in this study as long as they were used concurrently as was defined by Tobi et al (2007). Information concerning type of cancer and comorbidities was collected by medical chart review. In this study, comorbidities were defined as all other diseases an individual patient might have, other than the primary disease of interest (cancer).

Renal function [creatinine] and liver function parameters (aspartate aminotransferase (AST), alanine aminotransferase (ALT), and $\gamma$-glutamyltransferase $(\gamma$-GT)) were extracted from the laboratory database of the hospital while an individual patient was receiving an oral anticancer agent. Laboratory abnormalities were defined as an increase of $>50 \%$ above the upper limit of normal (upper normal limits in all three medical centres: ASAT $\leqslant 35 \mathrm{U} / \mathrm{L}, \mathrm{ALAT} \leqslant 40 \mathrm{U} / \mathrm{L}, \gamma-\mathrm{GT} \leqslant 44 \mathrm{U} / \mathrm{L}$, creatinine $\leqslant 99$ $\mu \mathrm{mol} / \mathrm{L})$.

Potential drug-drug interactions between drugs and over-thecounter (OTC) medication were not studied. When a drug formulation contained two or more pharmacologically active ingredients each drug was counted individually in the analysis (e.g., tramadol/acetaminophen). However, when a patient was taking the same medication in more than one formulation (e.g., long- and short-acting morphine) the drug was counted only once.

In this study, we have identified drug-drug combinations, within the same patient, for drugs that are known for having interacting effects, rather than the occurrence of an actual adverse event in an individual patient. Potential drug-drug interactions were identified by using the Drug Interaction Facts software (Facts and Comparisons, version 4.0, 2006), which is a commonly used and reputable source. It has been shown to have an accuracy of 
over 95\% in detecting interactions (Barrons, 2004). Drug Interaction Facts software classifies interactions by the level of severity and the level of scientific evidence. A detailed classification of level of severity and scientific evidence is shown in Figure 1.

The medication regimen of each patient was also screened for:

1. Drug combinations with potential QT-interval prolongation and/or torsades de pointes inducing properties using the Arizona CERT system list 1 (risk of torsades) and list 2 (possible risk of torsades) (Scientific Advisory Board of the Arizona Centre for Education and Research on Therapeutics (CERT)). Because of the potentially severe consequences, all drug combinations with risk for QT prolongation were classified as major (QT interaction). The QT-interval prolonging potential of drugs is generally well documented and QT interactions were classified as 'probable' as was defined in Figure 1.

2. Drugs associated with an increased risk of falling (central nervous system (CNS)-depressant agents). First, the medication regimen of each patient was manually screened for CNSdepressant agents by using handbooks and peer-reviewed reports on scientific evidence (Leipzig et al, 1999; Lord et al, 2003; Tinetti, 2003; Hartikainen et al, 2005; Gralow et al, 2009; Woolcott et al, 2009). A combination of two CNS-depressant agents was counted as one interaction and defined as CNS interaction in the analysis. All CNS interactions were classified as moderate. The CNS-depressant potential of drugs is described in the literature, and CNS interactions were classified as 'probable' as was defined in Figure 1.

3. Drug combinations between non-steroidal anti-inflammatory drugs (NSAIDs) and corticosteroids, anticoagulants, aspirin, bisphosphonates, or selective serotonin reuptake inhibitors (SSRIs). These combinations were defined as a gastrointestinal (GI) interaction and were identified by using the Drug Interaction Facts software and peer-reviewed reports on scientific evidence (Piper et al, 1991; Lanza, 1998; Singh, Rosen Ramey (1998)). The GI interactions may increase the risk of GI bleeding. Due to the potentially severe consequences all GI interactions were classified as major. The GI interactions are generally well documented, and were classified as 'probable' as was defined in Figure 1.

A PDDI was only counted in the analysis when an 'anticancer agent' or a 'supportive care drug' was involved; thus, PDDIs resulting from the treatment of comorbidities were disregarded. Interactions of minor severity, being clinically not relevant, were not included in the analysis.

Statistical analysis. To compute patient demographics, cancer type, comorbidities, number of drugs used per patient, laboratory abnormalities, and drug interaction characteristics (severity, scientific evidence, and mechanism), descriptive statistics were used. Subsequently, univariate and multivariate binary logistic regression analyses were performed to identify the potential risk factors for the occurrence of PDDIs. The occurrence of at least one DDI per patient was called the dependent variable. Predictor variables tested included age, number of drugs, presence of comorbidities (yes/no), cancer type, treatment type, solid tumour or haemato-oncology disease and laboratory abnormalities. Gender was not included as a predictor variable as certain cancer types only occur in men or women. The largest group per predictor variable was taken as the reference (Ref.) for binary or nominal variables. In the multivariate analysis predictor, variables with univariate $P$-values $<0.1$ were included. Predictor variables in the multivariate analysis with a $P$-value of $<0.05$ were considered statistically significant. The data were adjusted for confounders and effect modifiers. Data were collected and analysed in SPSS version 15.0 (SPSS Inc., Chicago, IL, USA).

\section{RESULTS}

Patient. A total of 898 patients were included in this study, with a median age of 61 years (range 18-95 years), of which 58\% were female. The median number of drugs used per person was five (range 1-24 drugs). Demographic characteristics are listed in Table 1. In 898 patients, a total of 31 different oral anticancer drugs were identified as stated in Table 2.

Drug interactions. In total, 1359 PDDIs were identified in 426 patients (46\%, 95\% CI =42-50\%; Figure 2). In 143 patients $(16 \%)$ at least one major PDDI was identified. Of all PDDIs, $15 \%$ and $83 \%$ were classified as major and moderate PDDIs, respectively. In $14 \%$ of all PDDIs, anticancer drugs were involved. A pharmacodynamic PDDI was found in $86 \%$ of all cases. The majority of cases concerned CNS interactions $(n=848)$, GI interactions $(n=97)$, and QT interaction $(n=45)$. Most PDDIs $(86 \%)$ were supported by level 2 (probable) or level 3 (suspected) scientific evidence. A stratification of the identified PDDIs by 'level of severity', 'level of scientific evidence', and 'mechanism of drug interaction' is listed in Figure 2.

Potential drug-drug interactions involving anticancer drugs and supportive care agents are listed in Table 3. As the variety of drug classes is diverse, only PDDIs with potentially major consequences are reported. The drug classes most commonly involved in major PDDIs were coumarins and opioids. The QT interactions and GI interactions were also observed frequently.

Risk factors. All patients were included in the binary logistic regression analysis. In the univariate analysis, the number of drugs, treatment type, cancer type, and the presence of comorbidities were associated with higher risk for PDDIs. No statistically significant association was found for age $(P=0.124)$, tumour type (solid/non-solid malignancy; $P=0.327$ ), or laboratory abnormalities $(P=0.295)$. Results of the univariate and multivariate binary logistic regression analyses are listed in Table 4 . After adjustment for confounders, the number of drugs (odds ratio (OR) 1.66

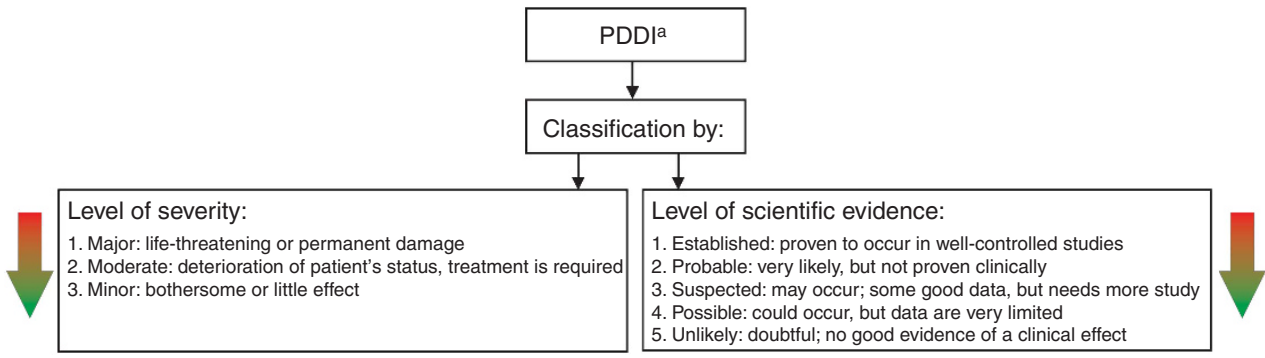

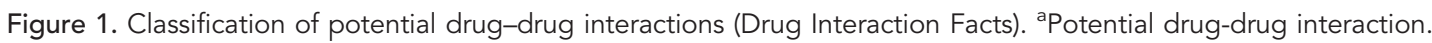




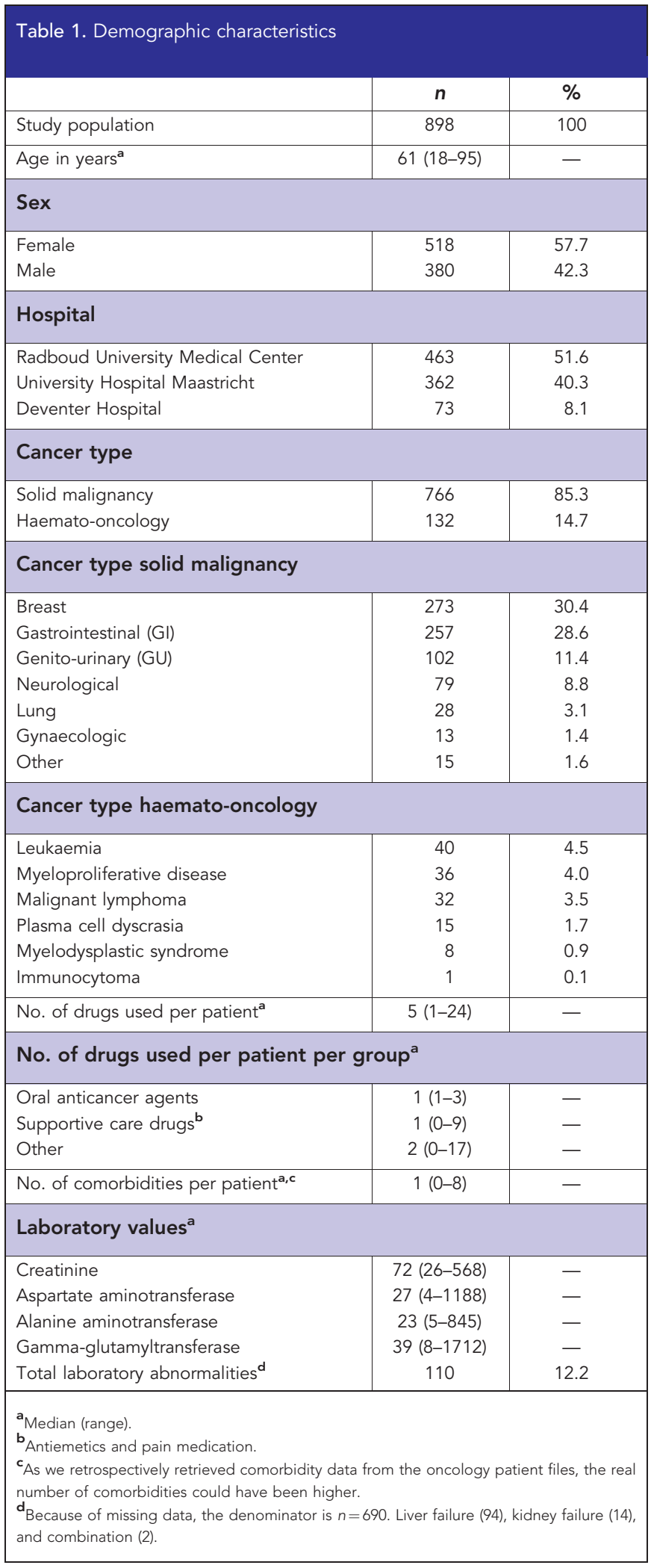

(1.54-1.78); $P<0.0001)$ and cancer type (genito-urinary cancer, OR $0.25(0.12-0.52) ; P<0.0001)$ remained statistically significant.

\section{DISCUSSION}

To our knowledge, this is the first study to investigate the prevalence of PDDIs among cancer patients that are on oral
Table 2. Oral anticancer drugs identified

\begin{tabular}{|c|c|}
\hline $\begin{array}{l}\text { Drug class } \\
\text { (ATC code) }\end{array}$ & Drugs $(n)$ \\
\hline \multicolumn{2}{|l|}{ Oncolytics (L01) } \\
\hline Alkylating agents & $\begin{array}{l}\text { Temozolomide (75), Chlorambucil (34), } \\
\text { Cyclophosphamide (26), Lomustine (9), Melphalan (9), } \\
\text { Procarbazine (9), Busulfan (1) }\end{array}$ \\
\hline Antimetabolites & $\begin{array}{l}\text { Capecitabine (258), Hydroxyurea (41), Fludarabine (9), } \\
\text { Mercaptopurine (8), Thioguanine (3), Uracil-Tegafur } \\
\text { (2), Methotrexate (1) }\end{array}$ \\
\hline $\begin{array}{l}\text { Protein kinase } \\
\text { inhibitors }\end{array}$ & $\begin{array}{l}\text { Imatinib (30), Sunitinib (27), Erlotinib (10), Dasatinib } \\
\text { (9), Nilotinib (8), Sorafenib (4), Everolimus (4), } \\
\text { Thalidomide (1) }\end{array}$ \\
\hline $\begin{array}{l}\text { Topoisomerase } \\
\text { inhibitors }\end{array}$ & Etoposide(19), Topotecan (1) \\
\hline Other oncolytics & Tretinoin (3) \\
\hline \multicolumn{2}{|c|}{ Antihormonal agents (L02) } \\
\hline Anti-oestrogens & Tamoxifen (171) \\
\hline Enzyme inhibitors & Anastrozole (75), Letrozole (29), Exemestane (5) \\
\hline Anti-androgens & Bicalutamide (76), Flutamide(3) \\
\hline
\end{tabular}

anticancer treatment. In this analysis, we detected a high prevalence of PDDIs with $46 \%$ of all patients being exposed to at least one PDDI. More importantly, these PDDIs were not just theoretical in nature, $16 \%$ of all patients had at least one major PDDI that may have had harmful side effects and which usually would have needed intervention or intensive monitoring.

Most PDDIs (86\%) were supported by level 2 or level 3 scientific evidence. In the majority of PDDIs, a supportive care agent was involved (86\%). Potential drug-drug interactions with coumarins, whose anticoagulant effects may be altered, and fentanyl, through which plasma concentrations and toxicity of fentanyl may be increased, were most frequently registered. This also counted for drug combinations that may have led to QT-interval prolongation, or to GI toxicities. The highest prevalence concerned CNS interactions that accounted for up to $73 \%$ of all PDDIs.

The drug-drug combinations of coumarins with certain oral anticancer agents (e.g., capecitabine) may result in altered anticoagulant effects and haemorrhage due to the increased hypoprothrombinemic effects of coumarins (Ritchie and Grant, 1989; Nakajima et al, 2010; Shah et al, 2010). In case of a PDDI, anticoagulant effects should be closely monitored and the dose of coumarins must be adjusted accordingly. Combinations of strong CYP3A4 iso-enzyme inhibitors/inducers and anticancer drugs can be potentially harmful (Kehrer et al, 2002; Mathijssen et al, 2002). In this study, the combination of fentanyl and strong CYP3A4 isoenzyme inhibitors (e.g., itraconazole) was frequently found. This CYP3A4 inhibitor may decrease the metabolic elimination of this opioid, resulting in increased plasma concentrations and pharmacologic effect of fentanyl. Closely monitoring for signs of excessive narcotic effects of fentanyl is indicated and dosage reduction may be required (Hallberg et al, 2006; Official package labelling Actiq (fentanyl citrate), 2007).

Drug combinations that could lead to QT-interval prolongation, or to GI toxicity, can have serious or even fatal consequences, like torsade de pointes and NSAIDs induced ulcers, respectively (Scientific Advisory Board of the Arizona Center for Education and Research on Therapeutics (CERT); Piper et al, 1991; Lanza, 1998). Due to the extensive use of QT-prolonging drugs 


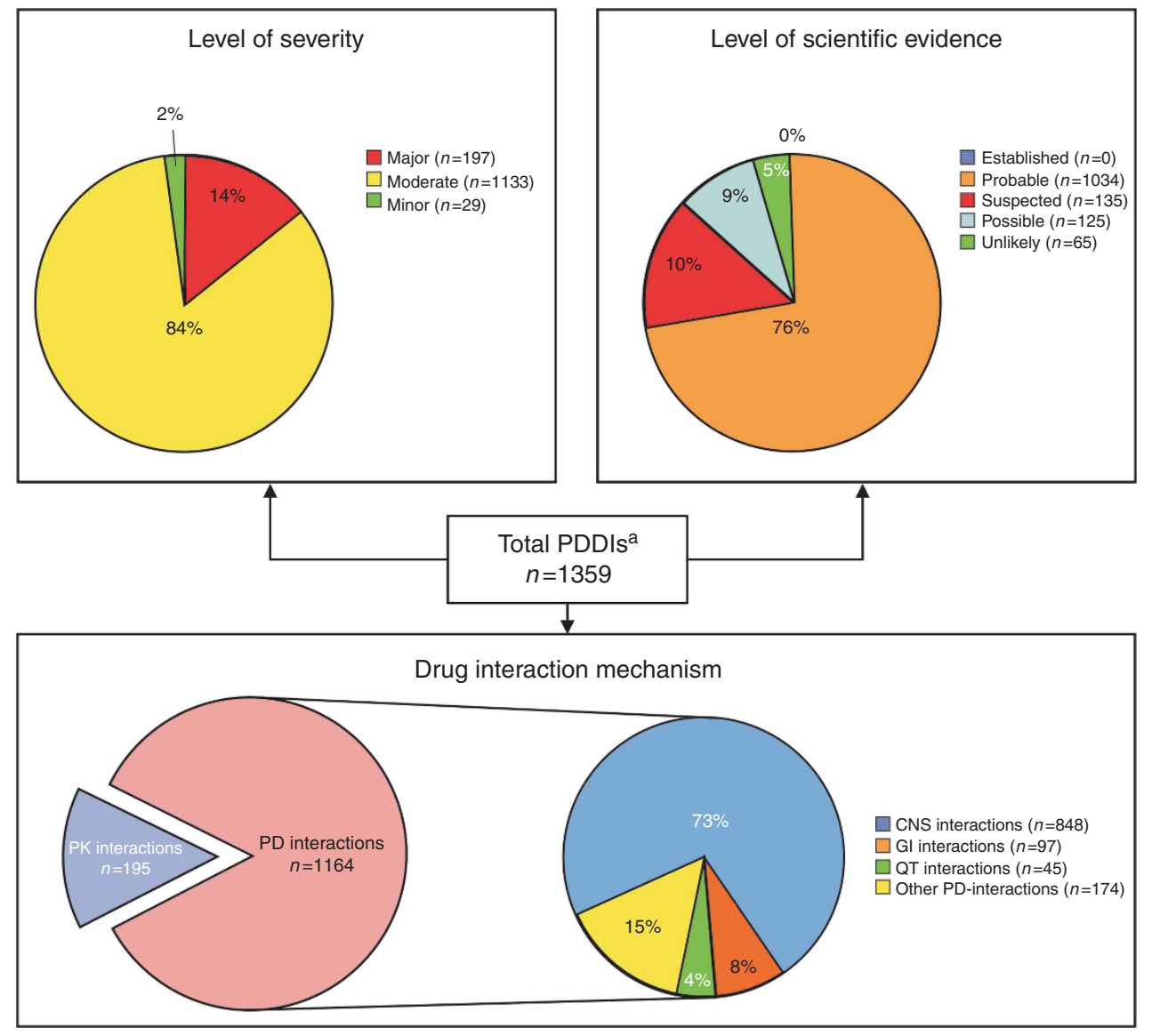

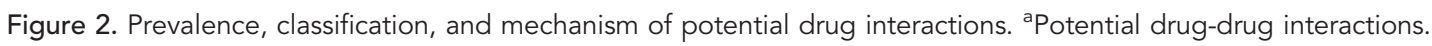

(e.g., ondansetron) and drugs that can cause GI toxicity (e.g., NSAIDs) in (haemato)-oncology these PDDIs may cause significant health risks. Concerning QT interactions, there is very little information to guide clinicians about the risks of concomitantly using QT-prolonging drugs, and how these PDDIs should be managed. Moreover, the evidence for risk of Torsades de point is often imperfect. Nevertheless, QT interactions are presumed to have the potential for life-threatening consequences. Drug-drug combinations that could lead to QT-interval prolongation or to GI toxicity should, if possible, be avoided.

The high prevalence of CNS interactions is of particular concern, since injuries resulting from balance disorders may have a major impact on public health. The authors acknowledge that a large number of cancer patients need CNS depressant medication (e.g., opioids, antidepressants, and benzodiazepines). However, due to the increased risk of osteoporosis and the extensive use of CNSdepressant drugs, cancer patients are particularly at risk for fractures (Gralow et al, 2009). Prescribed CNS-depressant drugs can result in an up to $47 \%$ increased risk of falls (Landi et al, 2005). Prescription of combinations of CNS-depressant drugs may even further increase this risk (Hartikainen et al, 2005). Although combinations of CNS-depressant drugs are often used for therapeutic reasons, oncologists and other health-care professionals should minimise the number of CNS depressant drugs prescribed, or at least carefully assess combinations of CNSdepressant drugs and monitor for signs of balance disorders.

In this study, the number of drugs used concomitantly has been identified as a risk factor for the occurrence of PDDIs. Genitourinary cancer showed a lower risk. It is not surprising that an increasing number of drugs used is associated with an increased risk of PDDIs and is in agreement with other studies (Riechelmann et al, 2007; van Leeuwen et al, 2011). Patients with genito-urinary cancers were less likely to be exposed to PDDIs. A plausible explanation for this lower risk could be the relatively mild interaction profile of bicalutamide, which was predominately used for the oral treatment of prostate cancer in our studied population. However, many medical centres still use flutamide and nilutamide for the treatment of prostate cancer, which do have interacting potentials. This questions the generalisability of prostate cancer as a risk factor.

A great strength of this study was that the medication data in the computer-based medication prescription system were based on 'actual concurrent use' (Tobi et al, 2007). If an oral anticancer drug was dispensed in the hospital pharmacy, then the actual use of other drugs (e.g., supportive care drugs' and 'drugs to treat additional diseases/comorbidities'), both on a continuous base and an incidental use, was always discussed with the patient and registered in the computer-based medication prescription system. Other strengths of our study included the large multicentre sample size, cross-sectional design, use of a large variety of oral anticancer agents, objective identification of PDDIs based on highly sensitive screening software (Facts and Comparisons, version 4.0, 2006; Barrons, 2004 and the additional screening for QT, GI, and CNS interactions. These factors increase the validity and representativeness of this study.

A major limitation of this study is that it does not investigate the clinical impact of the PDDIs. Although Buajordet et al (2001) estimated that PDDIs are responsible for the death of $4 \%$ of hospitalised cancer patients, insights into the clinical consequences of PDDIs in cancer patients remains largely unknown and should be further explored in prospective studies. Also, the true relevance of some drug-drug interactions identified by Drugs Interaction 


\begin{tabular}{|c|c|c|c|c|}
\hline & n & Description & Severity & $\begin{array}{l}\text { Scientific } \\
\text { evidence }\end{array}$ \\
\hline \multicolumn{5}{|l|}{ Potential drug-drug interactions involving anticancer agents } \\
\hline $\begin{array}{l}\text { Tamoxifen + Ondansetron/Granisetron/Sotalol/Erythromycin/ } \\
\text { Levofloxacin/Methadone/Risperidone/Azithromycina (Scientific } \\
\text { Advisory Board of the Arizona Center for Education and Research } \\
\text { on Therapeutics (CERT)) }\end{array}$ & 28 & Drug combinations can prolong QT interval & Major & 2 \\
\hline $\begin{array}{l}\text { Coumarins + Capecitabine/Tamoxifen/Etoposide } \\
\text { (Ritchie and Grant, 1989; Shah et al, 2010) }\end{array}$ & 17 & $\begin{array}{l}\text { Hypoprothrombinemic effects of coumarins may be } \\
\text { increased, bleeding may occur }\end{array}$ & Major & 2 \\
\hline $\begin{array}{l}\text { Methotrexate + Sulfamethoxazole/Trimethoprim/Acetylsalicylic } \\
\text { acid (Bourré-Tessier and Haraoui, 2010; Seideman, Müller-Suur, } \\
\text { 1993) }\end{array}$ & 12 & $\begin{array}{l}\text { Increased pharmacologic effects of methotrexate with an } \\
\text { increased risk of bone marrow and hepatic toxicity }\end{array}$ & Major & 2 \\
\hline (Es)omeprazole + Dasatinib/Nilotinib (Yin et al, 2010) & 4 & $\begin{array}{l}\text { Proton pump inhibitors may decrease the plasma } \\
\text { concentration of tyrosine kinase receptor inhibitors }\end{array}$ & Major & 3 \\
\hline Methotrexate + Prednisolone (Koerber et al, 1994) & 2 & $\begin{array}{l}\text { Prednisolone may decrease the total clearance of } \\
\text { methotrexate }\end{array}$ & Major & 2 \\
\hline Methotrexate + Amoxicillin/Clavunate (Zarychanski et al 2006) & 1 & $\begin{array}{l}\text { Penicillins may decrease the total clearance of } \\
\text { methotrexate }\end{array}$ & Major & 4 \\
\hline Perphenazine + Tamoxifen (Sideras et al, 2010) & 1 & $\begin{array}{l}\text { Pharmacologic effects of tamoxifen may be decreased by } \\
\text { Perphenazine. Co-administration may increase the risk of } \\
\text { breast cancer recurrence }\end{array}$ & Major & 4 \\
\hline \multicolumn{5}{|c|}{ Potential drug-drug interactions involving supportive care drugs } \\
\hline $\begin{array}{l}\text { NSAIDs }{ }^{\mathbf{b}}+\text { Corticosteroids c/SSRIs }{ }^{\mathrm{d}} / \text { Dipyridamole/Clopidogel/ } \\
\text { Alendronate (Piper et al, 1991; Lanza, 1998) }\end{array}$ & 98 & Increased risk of Gl bleeding & Major & 2 \\
\hline $\begin{array}{l}\text { SSRIs + Metoclopramide/Tramadol (Fisher and Davis, 2002; } \\
\text { Houlihan, 2004) }\end{array}$ & 16 & Serotonin syndrome is a potential risk with this combination & Major & 4 \\
\hline $\begin{array}{l}\text { Fentanyl + Fluconazole/Aprepitant/Ketoconazole/Diltiazem/ } \\
\text { Itraconazole (Hallberg et al, 2006; Official Packaged labelling for } \\
\text { Actiq, 2007) }\end{array}$ & 12 & $\begin{array}{l}\text { Increased pharmacologic effects and plasma } \\
\text { concentrations of fentanyl }\end{array}$ & Major & 2 \\
\hline $\begin{array}{l}\text { Haloperidol + Granisetron/Metoclopramide } \\
\text { Ofloxacin + Methadone (Scientific Advisory Board of the Arizona } \\
\text { Center for Education and Research on Therapeutics (CERT)) }\end{array}$ & 5 & Drug combinations can prolong QT interval & Major & 2 \\
\hline Fluconazole + Methadone (Tarumi et al, 2002) & 1 & $\begin{array}{l}\text { Increased plasma concentration and pharmacologic effects } \\
\text { of methadone }\end{array}$ & Major & 4 \\
\hline \multicolumn{5}{|l|}{ 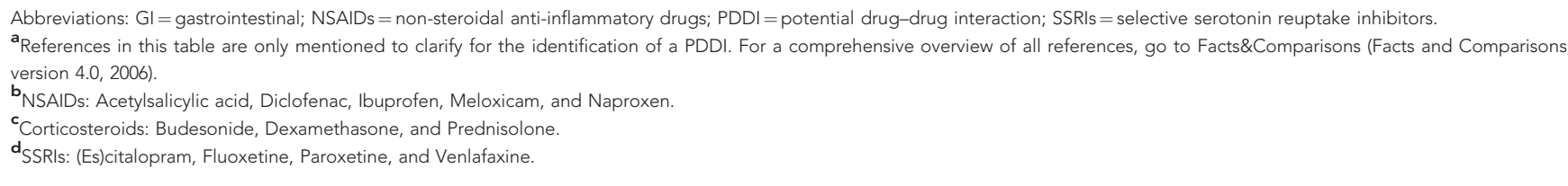 } \\
\hline
\end{tabular}

Facts software or the additional manual search may sometimes be questioned (e.g., NSAIDs and bisphosphonates or NSAIDs and SSRIs). Furthermore, it is not known to what extent precautions (e.g., dosage adjustments) were taken by the health-care professionals to prevent potentially harmful PDDIs. Since these precautions are not being accounted for in this study, this may lead to an over-detection of PDDIs by electronic PDDI databases, as was concluded by Chan et al (2011). Another limitation of this study was that we did not study PDDIs between prescription drugs and OTC medication. In our previous study (van Leeuwen et al (2011)), OTC drugs were involved in $11 \%$ of all PDDIs. Although drug combinations with OTC drugs were not investigated in this study (due to the retrospective search in the computer-based medication prescription system), PDDIs with OTC drugs are relevant and can be potentially harmful (Mathijssen et al, 2002; Tascilar et al, 2006).

Our findings were largely in accordance with other studies (Riechelmann et al, 2007; van Leeuwen et al, 2011). Conversely, a comparable retrospective database study, conducted in Eastern cancer patients using oral anticancer therapy, found that only $5 \%$ of all patients had at least one PDDI (Ko et al, 2012). A possible explanation for the higher prevalence of PDDIs in our study may be the additional search for QT, GI and CNS interactions. Nevertheless, the existence of potentially harmful PDDIs should not be neglected and needs the explicit attention of pharmacists and medical doctors.

In conclusion, over the past years there has been a sharp shift and focus towards oral anticancer drugs. The present study shows that besides their possible benefits, cancer patients on oral anticancer therapy are at considerable risk for PDDIs. It remains unknown to what extent pharmacies and medical doctors were actually aware of these PDDIs and whether they took adequate measures to prevent potentially harmful drug-drug combination. Therefore, the impact of the identified PDDIs on clinical outcomes remains partly unknown and should be further investigated in detail in future prospective studies. In the Erasmus University 
Table 4. Univariate and multivariate binary logistic regression analysis

\begin{tabular}{|c|c|c|c|c|}
\hline Variable & Unadjusted OR (95\% CI) & Unadjusted $P$-value & Adjusted OR (95\% Cl) & Adjusted $P$-value \\
\hline Age & $1.01(1.00-1.02)$ & 0.124 & - & - \\
\hline No. of drugs & $1.65(1.54-1.76)$ & $<0.0001$ & $1.66(1.54-1.78)$ & $<0.0001^{\mathrm{a}}$ \\
\hline \multicolumn{5}{|l|}{ Treatment type } \\
\hline $\begin{array}{l}\text { Oncolytics } \\
\text { Antihormonal agents } \\
\text { Others }\end{array}$ & $\begin{array}{c}1.0 \text { (Ref.) } \\
0.39(0.29-0.52) \\
2.12(0.79-5.66)\end{array}$ & $\begin{array}{c}- \\
<0.0001 \\
0.134\end{array}$ & $\begin{array}{l}1.0 \text { (Ref.) } \\
0.61(0.29-1.29) \\
1.27(0.32-5.05)\end{array}$ & $\begin{array}{c}- \\
0.196 \\
0.735\end{array}$ \\
\hline \multicolumn{5}{|l|}{ Cancer type } \\
\hline $\begin{array}{l}\text { Breast } \\
\text { Gastrointestinal } \\
\text { Haemato-oncology } \\
\text { Genito-urinary } \\
\text { Neuro-oncological } \\
\text { Other oncology }\end{array}$ & $\begin{array}{l}1.0 \text { (Ref.) } \\
2.35(1.66-3.34) \\
1.69(1.10-2.58) \\
0.53(0.31-0.91) \\
1.32(0.79-2.20) \\
2.99(1.66-5.41)\end{array}$ & $\begin{array}{c}<0.0001 \\
<0.016 \\
0.021 \\
0.293 \\
<0.0001\end{array}$ & $\begin{array}{l}1.0 \text { (Ref.) } \\
0.65(0.29-1.44) \\
0.45(0.19-1.06) \\
0.25(0.12-0.52) \\
0.59(0.24-1.49) \\
1.10(0.45-2.68)\end{array}$ & $\begin{aligned} & 0.290 \\
& 0.067 \\
&< 0.0001^{\mathrm{a}} \\
& 0.264 \\
& 0.832\end{aligned}$ \\
\hline \multicolumn{5}{|l|}{ Tumour type } \\
\hline $\begin{array}{l}\text { Oncology } \\
\text { Haemato-oncology }\end{array}$ & $\begin{array}{c}1.0 \text { (Ref.) } \\
1.20(0.83-1.75)\end{array}$ & $\overline{0.327}$ & - & - \\
\hline \multicolumn{5}{|c|}{ Presence of comorbidities } \\
\hline $\begin{array}{l}\text { No } \\
\text { Yes }\end{array}$ & $\begin{array}{c}1.0 \text { (Ref.) } \\
2.06(1.58-2.70)\end{array}$ & $<\overline{0.0001}$ & $\begin{array}{c}1.0 \text { (Ref.) } \\
1.02(0.70-1.48)\end{array}$ & $\overline{0.923}$ \\
\hline \multicolumn{5}{|c|}{ Laboratory abnormality } \\
\hline $\begin{array}{l}\text { No } \\
\text { Yes }\end{array}$ & $\begin{array}{l}1.0 \text { (Ref.) } \\
1.24(0.83-1.87)\end{array}$ & $\overline{0.295}$ & $\begin{array}{l}- \\
-\end{array}$ & - \\
\hline
\end{tabular}

Medical Centre, a prospective clinical trial such as this is currently ongoing, to explore important remaining questions. For instance, the effects of duration of anticancer drug treatment and the dose of the drugs that may interact will be studied in detail.

This is particularly relevant as with the increasing numbers of new oral anticancer agents that become available, the risk for PDDIs will consequently increase. Despite this fact, in current daily practice medication review is not always common practice. We realise that many combinations of interacting drugs are unavoidable and may be administered together if appropriate precautions are taken (e.g., monitoring and dosage adjustment). However, this requires a solid medication review of all drugs used at every patient visit by an oncologist or pharmacist. Therefore, in an ideal situation, all drugs prescribed by oncologists, general practitioners, and other health-care professionals should be documented electronically, including patient's medical status, in computerbased patient records to identify and prevent potentially harmful PDDIs.

\section{ACKNOWLEDGEMENTS}

We would like to thank all participating (hospital) pharmacists in the Maastricht University Medical Center, Radboud University Nijmegen Medical Center and Deventer Hospital for their contributions to in this study. We also thank Patty Nelemans (epidemiologist, Maastricht University Medical Center) for her critical review of methods used, Hans Kneefel for the graphical design of the figures, and Stacy Crow (pharmD) for proof-reading and editing the manuscript. This study was supported by the Maastricht University Medical Center. The funding source had no role in study design, data collection, data analysis, data interpretation, or writing of the manuscript. All authors had full access to the raw data of the study. The corresponding author had the final responsibility for the decision to submit the data for publication.

\section{CONFLICT OF INTEREST}

The authors declare no conflict of interest.

\section{AUTHORS CONTRIBUTIONS}

RWFvL, CN, DMB, and FGAJ designed the study. RvL and DHSB included the patients. RvL, CN, TvG, RHJM, DMB, and FJ evaluated the study data and wrote the manuscript.

\section{REFERENCES}

Drug Interaction Facts. Version 4.0. (2006) Wolters Kluwer Health. Available at: http://www.factsandcomparisons.com (Last consulted on 16 January 2013).

Scientific Advisory Board of the Arizona Center for Education and Research on Therapeutics (CERT) QT Drug Lists. Available at: http://www.arizonacert. org (Last consulted on 16 January 2013).

Aisner J (2007) Overview of the changing paradigm in cancer treatment: oral chemotherapy. Am J Health Syst Pharm 64(suppl 5): S4-S7. 
Barrons R (2004) Evaluation of personal digital assistant software for drug interactions. Am J Health Syst Pharm 61: 380-385.

Bourré-Tessier J, Haraoui B (2010) Methotrexate drug interactions in the treatment of rheumatoid arthritis: a systematic review. J Rheumatol 37: 1416-1421.

Brummett RE (1981) Ototoxicity resulting from combined administration of potent diuretics and other agents. Scand Audiol Suppl 14(suppl): 215-224.

Buajordet I, Ebbesen J, Erikssen J, Brørs O, Hilberg T (2001) Fatal adverse drug events: the paradox of drug treatment. J Intern Med 250: 327-341.

Egger SS, Drewe J, Schlienger RG (2003) Potential drug-drug interactions in the medication of medical patients at hospital discharge. Eur J Clin Pharmacol 58: 773-778.

Fisher AA, Davis MW (2002) Serotonin syndrome caused by selective serotonin reuptake-inhibitors-metoclopramide interaction. Ann Pharmacother 36: 67-71.

Chan A, Yap KY, Koh D, Low XH, Cheung YT (2011) from the OncoInformatics (onco-informatics.com) Group. Electronic database to detect drug-drug interactions between antidepressants and oral anticancer drugs from a cancer center in Singapore: implications to clinicians. Pharmacoepidemiol Drug Saf 20: 939-947.

Geppert U, Beindl W, Hawranek T, Hintner H (2003) Drug interactions in clinical practice. A pilot project for quality assurance in prescribing. Hautarzt 54: 53-57.

Glintborg B, Andersen SE, Dalhoff K (2005) Drug-drug interactions among recently hospitalised patients-frequent but mostly clinically insignificant Eur J Clin Pharmacol 61: 675-681.

Gralow JR, Biermann JS, Farooki A, Fornier MN, Gagel RF, Kumar RN, Shapiro CL, Shields A, Smith MR, Srinivas S, Van Poznak CH (2009) NCCN Task Force Report: Bone Health in Cancer Care. J Natl Compr Canc Netw 7(Suppl 3): S1-32.

Hallberg P, Martén L, Wadelius M (2006) Possible fluconazole-fentanyl interaction-a case report. Eur J Clin Pharmacol 62: 491-492.

Hartikainen S, Mäntyselkä P, Louhivuori-Laako K, Enlund H, Sulkava R (2005) Concomitant use of analgesics and psychotropics in homedwelling elderly people-Kuopio $75+$ study. $\mathrm{Br}$ J Clin Pharmacol 60: 306-310.

Houlihan DJ (2004) Serotonin syndrome resulting from coadministration of tramadol, venlafaxine, and mirtazapine. Ann Pharmacother 38: 411-413.

Kehrer DF, Mathijssen RH, Verweij J, de Bruijn P, Sparreboom A (2002) Modulation of irinotecan metabolism by ketoconazole. J Clin Oncol 20: 3122-3129.

Ko Y, Tan SL, Chan A, Wong YP, Yong WP, Ng RC, Lim SW, Salim A (2012) Prevalence of the coprescription of clinically important interacting drug combinations involving oral anticancer agents in Singapore: a retrospective database study. Clin Ther 34: 1696-1704.

Koerber H, Gross WL, Iven H (1994) Do steroids influence low dose methotrexate pharmacokinetics? J Rheumatol 21: 1170-1172.

Köhler GI, Bode-Böger SM, Busse R, Hoopmann M, Welte T, Böger RH (2000) Drug-drug interactions in medical patients: effects of in-hospital treatment and relation to multiple drug use. Int J Clin Pharmacol Ther $\mathbf{3 8}$ 504-513.

Landi F, Onder G, Cesari M, Barillaro C, Russo A, Bernabei R (2005) Silver Network Home Care Study Group. Psychotropic medications and risk for falls among community-dwelling frail older people: an observational study. J Gerontol A Biol Sci Med Sci 60: 622-626.

Lanza FL (1998) A guideline for the treatment and prevention of NSAIDinduced ulcers. Members of the Ad Hoc Committee on Practice Parameters of the American College of Gastroenterology. Am J Gastroenterol 93: 2037-2046.

Leipzig RM, Cumming RG, Tinetti ME (1999) Drugs and falls in older people: a systematic review and meta-analysis: I. Psychotropic drugs. Am Geriatr Soc 47: 30-39.

Lord SR, Menz HB, Tiedemann A (2003) A physiological profile approach to falls risk assessment and prevention. Phys Ther 83: 237-252.

Mathijssen RH, Verweij J, de Bruijn P, Loos WJ, Sparreboom A (2002) Effects of St. John's wort on irinotecan metabolism. J Natl Cancer Inst 94: 1247-1249.
Nakajima M, Genda T, Suehira M, Satoh H, Miki A, Hori S, Sawada Y (2010) Increased anticoagulant activity of warfarin used in combination. Cancer Chemother Pharmacol 66: 969-972.

Official package labeling for Actiq (fentanyl citrate). Cephalon, Inc.; Salt Lake City, UT (2007)

Piper JM, Ray WA, Daugherty JR, Griffin MR (1991) Corticosteroid use and peptic ulcer disease: role of nonsteroidal anti-inflammatory drugs. Ann Intern Med 114: 735-740.

Riechelmann RP, Tannock IF, Wang L, Saad ED, Taback NA, Krzyzanowska MK (2007) Potential drug interactions and duplicate prescriptions among cancer patients. J Natl Cancer Inst 99: 592-600.

Ritchie LD, Grant SM (1989) Tamoxifen-warfarin interaction: the Aberdeen hospitals drug file. BMJ 298: 1253.

Scripture CD, Figg WD (2006) Drug interactions in cancer therapy. Nat Rev Cancer 6: 546-558.

Seideman P, Müller-Suur R (1993) Renal effects of aspirin and low dose methotrexate in rheumatoid arthritis. Ann Rheum Dis 52: 613-615.

Shah SR, Martin R, Dowell JE, Ussery SM (2010) Comparison of the 5-fluorouracil-warfarin and capecitabine-warfarin drug interactions. Pharmacotherapy 30: 1259-1265.

Sideras K, Ingle JN, Ames MM, Loprinzi CL, Mrazek DP, Black JL, Weinshilboum RM, Hawse JR, Spelsberg TC, Goetz MP (2010) Coprescription of tamoxifen and medications that inhibit CYP2D6. J Clin Oncol 28: 2768-2776.

Singh G, Rosen Ramey D (1998) NSAID induced gastrointestinal complications: the ARAMIS perspective-1997. Arthritis, Rheumatism, and Aging Medical Information System. J Rheumatol Suppl 51: 8-16.

Tarumi Y, Pereira J, Watanabe S (2002) Methadone and fluconazole: respiratory depression by drug interaction. J Pain Symptom Manage 23: 148-153.

Tascilar M, de Jong FA, Verweij J, Mathijssen RH (2006) Complementary and alternative medicine during cancer treatment: beyond innocence. Oncologist 11: 732-741.

Tinetti ME (2003) Clinical practice. Preventing falls in elderly persons. N Engl $J$ Med 348: 42-49.

Tobi H, Faber A, van den Berg PB, Drane JW, de Jong-van den Berg LT (2007) Studying co-medication patterns: the impact of definitions. Pharmacoepidemiol Drug Saf 16: 405-411.

van Leeuwen RW, Swart EL, Boven E, Boom FA, Schuitenmaker MG, Hugtenburg JG (2011) Potential drug interactions in cancer therapy: a prevalence study using an advanced screening method. Ann Oncol 22: 2334-2341.

Verschraagen M, Kedde MA, Hausheer FH, Van der Vijgh WJF (2003) The chemical reactivity of BNP7787 and its metabolite mesna with the cytostatic agent cisplatin: comparsion with the nucleophiled thiosulfate, DDTC, glutathione and its disulfide GSSG. Cancer Chemother Pharmacol 51: 499-504.

Woolcott JC, Richardson KJ, Wiens MO, Patel B, Marin J, Khan KM, Marra CA (2009) Meta-analysis of the impact of 9 medication classes on falls in elderly persons. Arch Intern Med 169: 1952-1960.

Yancik R, Ries LAG (2000) Aging and cancer in America. Hematol Oncol Clin North Am. 14: 17-23.

Yin OQ, Gallagher N, Fischer D, Demirhan E, Zhou W, Golor G, Schran H (2010) Effect of the proton pump inhibitor esomeprazole on the oral absorption and pharmacokinetics of nilotinib. J Clin Pharmacol 50: 960-967.

Zarychanski R, Wlodarczyk K, Ariano R, Bow E (2006) Pharmacokinetic interaction between methotrexate and piperacillin/tazobactam resulting in prolonged toxic concentrations of methotrexate. J Antimicrob Chemother 58: $228-230$.

This work is published under the standard license to publish agreement. After 12 months the work will become freely available and the license terms will switch to a Creative Commons AttributionNonCommercial-Share Alike 3.0 Unported License. 